\section{WHO to aid Eastern Europe}

\section{Munich}

FEARS that a major epidemic of AIDS could occur in Eastern Europe has stimulated the World Health Organization (WHO) to join with national governments in a new preventive programme. The US government is making a grant of $\$ 1.5$ million but more will be needed.

Although there are very few AIDS cases in Eastern European countries - a total of just 306 was reported as at 31 December 1989 in seven Eastern European countries plus the Soviet Union WHO epidemiologist David Heymann said that "the potential is probably there" for a rapid spread of the disease.

In February, 550 children in Romania were found to be infected with HIV (human immunodeficiency virus), the virus that causes AIDS (see Nature 343, 579; 1990). Many will die before they reach the age of three. They are thought to have been infected through the use of unsterile needles used during 'microtransfusions' of blood and blood products.

At a meeting in Copenhagen last week, Eastern European countries for the first time reported the number of people infected with HIV (see chart). Bulgaria reported 154 known HIV-positive people, the Soviet Union 899 and Yugoslavia 1,713 . These countries estimate that up to three or four times as many people are really infected. The largest estimates are from countries where drug abuse is known to be a problem.

\section{CONSERVATION}

\section{British agencies need strong scientific base}

\section{London}

THE House of Lords Science and Technology committee has urged the British government to spend more to ensure that the separate English, Welsh and Scottish conservation agencies that will replace the Nature Conservancy Council (NCC) each have a strong scientific base. But the three agencies should not aim to be scientifically self-sufficient, the committee's report says. The joint committee that is to oversee the agencies should ensure cooperation and prevent duplication.

The report does not comment on the merits of the widely criticized decision to devolve the NCC (see Nature 343, 4 \& 15; 4 January 1990), but says the government's Environment Protection Bill, which proposed the change, "shows signs of hasty drafting". In particular, the committee wants the bill amended so that the joint committee can make legally binding decisions in the event of disputes between agencies.

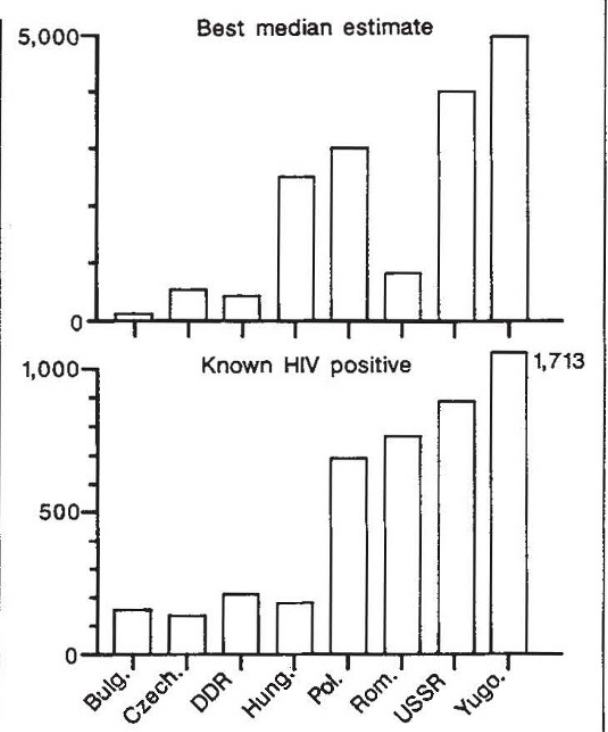

AIDS in Eastern Europe. Data courtesy WHO.

At the invitation of the governments, WHO will help set up AIDS education, testing and monitoring programmes in all Eastern European countries except Albania, which claims that it has no cases of AIDS. WHO will help each country to formulate an 'action plan' against AIDS after assessing the spread of the disease and the steps already being taken to prevent transmission of the virus.

WHO activities will include an Eastern European workshop on education and public information in Dresden in May and an exhibition on AIDS and youth in Warsaw in June. All countries reported that they were screening "100 per cent" of blood and blood products used in transfusions. Heymann said that some may be using home manufactured test kits. He stressed that the kits must be tested to be sure that they meet international standards. Tests that give false negative results could be very harmful, he said.

After the evaluations are complete, the next step will be to begin testing and reporting of AIDS cases. WHO will help monitor the spread of AIDS by testing blood samples taken from unnamed individuals for other medical reasons. WHO will convene a meeting of Western governments and private donors in August to discuss concrete help for individual Eastern European countries.

WHO officials welcome the change in attitude seen in Eastern European countries which have previously denied that there was an AIDS problem. Heymann said in the past six months, mandatory testing of risk groups had been abandoned in favour of widespread voluntary testing and counselling. WHO this week sent an epidemiologist to Romania to help the government trace the origins of the AIDS outbreak there.
Placebo or no placebo?

London

WORLDWIDE concern that experimental drugs for the treatment of AIDS may be withheld from patients while still under test has led British and French researchers to take a novel approach to the design of clinical trials for dideoxyinosine (ddI). The drug may help to prolong the lives of people with AIDS.

Tony Pinching, from St Mary's Hospital, London, who will run the British trial, says that unlike US pilot studies on ddI, his trial will allow patients to choose whether or not they join an experimental group which includes a placebo treatment. One group (option A), will be a standard randomized trial, with patients allocated across a placebo group, and low- and highdose ddI treatments. Option B will exclude the placebo, so patients can be sure that they are receiving ddI.

US ddI trials have demanded a strict scientific protocol, including placebos. But pressure from AIDS activists led to widespread 'compassionate release' of the drug by its manufacturers, Bristol-Myers Squibb, under the Food and Drug Administration's 'treatment IND' (investigational new drug) measure (see Nature 340, $331 ; 1989)$. Pinching estimates that about ten times more people have received ddI in this way than through the bettermonitored experimental trials.

The Medical Research Council (MRC), which is funding the British trial, says that the design will ensure that "all eligible patients can be entered into a formal study". Although there were doubts about whether many AIDS patients would volunteer for the option that included a placebo, Pinching says that, after consulting researchers, "some patients are already booked into option A".

The only drug at present licensed in Britain for treatment of AIDS is Wellcome's zidovudine (AZT), but 30-40 per cent of patients have to come off AZT within a year of treatment because of its toxic side-effects (including nausea, anorexia and muscle wasting). The new trial will look at the effects of ddI in several hundred of these AZT-intolerant patients.

Like AZT, ddI inhibits the enzyme reverse transcriptase, to slow replication of the human immunodeficiency virus (HIV). US trials have shown that ddI decreases the amount of HIV antigen circulating in the blood of AIDS patients, but there is no firm evidence yet of beneficial clinical effects comparable to those of AZT. The new trials will also look for toxic side-effects of ddI - some numbness and inflammation of the pancreas was reported in the US trials.
Peter Aldhous 